\title{
Methylation Pattern of Repetitive Elements in Correlation with Genome Wide Global DNA Methylation in the Prognosis of Paediatric Tuberculosis
}

\author{
Gayathri Pandurangan, Noyal Mariya Joseph and Mahadevan Subramaniyan* \\ ${ }^{1}$ Department of Pediatrics, ${ }^{2}$ Department of Microbiology, Jawaharlal Institute of \\ Postgraduate Medical Education and Research (JIPMER), Puducherry, India \\ *Corresponding author
}

\section{Keywords}

Genome wide DNA

Methylation, 5- MC

Quantification,

Methylation

Specific-PCR,

Paediatric

Tuberculosis, SINE(Alu), LINE1 methylation\&

Hypomethylation of REs.

\section{Article Info}

Accepted:

04 November 2020

Available Online:

10 December 2020

\section{A B S T R A C T}

Epigenetic modulation plays a vital role in regulating the transcriptional machinery of human genome in response to infection. Differential Methylation pattern of the genome especially the retro transposon repetitive elements (RE) which constitutes more than $45 \%$ of the genome had been studied to trace the impact of RE methylation in the disease severity. The correlation of the levels of genome wide DNA methylation and the methylation levels of LINE1 (Long interspersed transposable elements), SINE- Alu (Short interspersed transposable elements) repetitive elements (RE) showed the influence of repetitive elements in the prognosis of Mycobacterium tuberculosis among pediatric population. In comparison with healthy controls in this study we have investigated the association of methylation status altering the transcriptome involved in eliciting immune response. Investigating the levels of methylation of the repetitive elements will be an index to analyze the genome wide methylation which implicates the severity of the disease. Genome wide Methylation profiling could also be a potential biomarker to correlate with the prognosis of tuberculosis. The global methylation status of children infected with TB was found to be significantly differentiated when compared with healthy children. The methylation pattern of the repetitive elements LINE1\&SINE (Alu) were also found to be significantly differentiated with that of controls. Significant genome wide hypomethylation was observed in children infected with TB (9\% (IQR, 7\%-10\%) in comparison with healthy children (22\% (IQR, 18\%-24\%) ( $\mathrm{P}<0.001)$. The repetitive elements LINE1 and SINE (Alu) in accordance with global methylation of the genome were found to be hypomethylated in children infected with TB. The percentage of LINE1 Methylation was $22 \%$ (IQR, 20\%-26\%) in cases and 67\% (IQR 62-70\%) in controls $(\mathrm{P}<0.0001$ ) respectively. Similarly, remarkable difference in the levels of SINE(Alu) Methylation was found between cases (27\% (IQR 24-30\%) and controls 65\% (IQR 58-68\%) (P <0.0001)

\section{Introduction}

Tuberculosis (TB) is a disease with significant global threat. According to WHO report 2020Tuberculosis is a leading cause of death from a single infectious agent and ranks above HIV/AIDS as a key cause of death globally. Among 10.0 million people (1.0 million children) infected with TB, around 1.3 million people die worldwide. Though the 
mortality rate of TB has decreased from 1.8 since 2000 , still there is an alarming need to eradicate TB(TB WHO, 2020.). TB burden in children is huge and often grabs less attention. Around $69 \%$ of children <5years infected with TB have been ignored from treatment due to poor management in diagnosis and reporting. Among 1 million infected children (aged 0-14), 233000 children died in 2017 according to WHO report 2020. Unfortunately $96 \%$ of the pediatric deaths were observed in children who did not access TB treatment and $80 \%$ were less than $5 \mathrm{yrs}$ of age(WHO Childhood TB, 2018). Children becoming succumbed to tuberculosis disease could be due to the variation in the underlying epigenome with respect to immunological function. Upon infection the host immune system particularly the innate immune molecules undergoes massive transcriptional sequel of reactions to activate the genes involved in establishing first line defense and subsequent cellular immunity(Bierne et al., 2012; Jenner and Young, 2005).

On the other hand, the organism adopts mechanisms to evade host immunity by deregulating the transcriptional machinery of host involved in establishing immunity. However specific activation and silencing of genes in response to infection does not only depends on the transcriptional factors but the epigenetic modulators to trigger a gene (Bierne et al., 2012). Epigenetic modifications are the crucial modifications which implicate the expression of a gene to regulate various cellular processes in response to external stimuli, while the sequence of the genome remains intact. Epigenetic factors like DNA Methylation, Histone modification, chromatin associated complexes, non-coding RNAs, Splicing RNAs can impact the activation of immune molecules which would either lead to successful establishment of immunity or diseased state. Some of the cellular processes where epigenetic regulations have a key role are in maintaining chromosomal integrity, genome imprinting, $\mathrm{x}$ chromosome inactivation, embryonic development, etc (Yadav et al., 2016; Robertson KD, 2005). DNA methylation is the most prominent epigenetic regulation than the other epigenetic phenomenon as it directly obstructs the expression of a gene while the other plays much of post translational silencing. DNA methylation is a reversible chemical change occurs when DNA methyltransferases(DNMTs) shifts a methyl group covalently to the cytosine ring of a DNA at the C-5 position using Sadenosylmethionine as co-factor(Edwards et al., 2017; Jin et al., 2011).In mammals DNA methylation is carried out by DNA methyl transferases and methyl $\mathrm{CpG}$ binding proteins (MBDs) to maintain and to read the methylation marks respectively. It has been found that DNA methylation happens predominantly at the cytosines of a genome in a sequence context of $5^{\prime} \mathrm{CpG} 3$ ' and in response to stress and infection over $98 \%$ of DNA methylation was observed to happen in CpG dinucleotides of somatic cells(Bird, 2002; Lister et al., 2009; Robertson, 2002). In general, $\mathrm{CpG}$ islands overlap the 5' end of a gene possessing the promoter and an initial exon, almost $40 \%$ of promoters and exon regions of a genome are linked with $\mathrm{CpG}$ islands. CpGs are found to be presented in unmethylated state in somatic cells in normal condition.

However a well-established and maintained DNA methylation pattern of the genome is much essential to maintain the homeostasis of the body (Bird, 2002; Takai and Jones, 2002). Hypomethylated state of Repetitive Elements (RE) which constitutes more than $45 \%$ of the whole genome depicting the global DNA methylation will result in destabilizing the chromosomal integrity and thereby paves way for onset of many diseases. RE are presented in 2 major types, one of which is satellite or 
tandem repeats likely to be presented in adjacent forms while the other type shows interspread repeats which are the repeated sequences spread throughout the genome. Interspread repeats are also termed as mobile DNAs or transposons. Majority of such transposon activity in human is carried out by LINE1 and SINE (Alu) and are typically in hypermethylated state in a balanced niche. LINE1 in hypomethylated state could rearrange the genome as transposon insertion sequence and thereby influence the transcription of many functional genes(Baba et al., 2018; Consortium, 2001; Elbarbary et al., 2016; Robertson, 2005). Recent studies suggest that hypomethylated state of LINE1 and Alu repeats could be a trigger for diseases development and can also be a potential biomarker to detect the prognosis of a disease(Aparicio et al., 2009; Baba et al., 2018; Huen et al., 2016; Marques-Rocha et al., 2016; Wright et al., 2010).

In context to Mycobacterium tuberculosis infection histone monomethylated state of Alu repeats were reported to have widespread control over the transcriptional factors of SP1,p53, c-MYC, ANRIL, NF- kB,MEF2 and ATF families, and nuclear receptors LXR and RAR which plays vital role in macrophage differentiation and elicitation in response to infection and activating innate immunity (Bouttier et al., 2016).

In spite of studies evaluating the genome wide methylation status in metabolic disorders were reported, with respect to $\mathrm{TB}$ infection, it's still an area to be explored. Enumerating the pattern of DNA methylation in the repetitive elements LINE1 and SINE(Alu), subsequently comparing with the percentage of genome wide 5- methyl Cytosine (5-mC) content will provide an insight on the impact of genome wide DNA methylation in TB prognosis (Fig. 1-6).

\section{Materials and Methods}

\section{Study participants}

To correlate the levels of genome wide DNA methylation with the severity of tuberculosis disease, Paediatric patients infected with TB (Cases) aged 2-14yrs of both genders and healthy children (Controls) were recruited for the study. Ethical clearance was obtained from the Institutional Ethics committee. The subjects aged above 7 and the parents/ LAR were explained about the purpose of sample collection. Written informed consent was obtained from the study participants (cases and controls). Children showing clinical signs of infection with TB, abnormal Chest X-ray indicating $\mathrm{TB}$, positive TST, AFB smear positive, culture positive, positive Cartridge based nucleic acid amplification test were included in the study. Both pulmonary and extra-pulmonary tuberculosis cases were included in the study. In comparison healthy controls were recruited matching age and gender with that of study subjects. Healthy controls were children aged 2-14 with no history/signs of $\mathrm{TB}$ or any other lung infection/disease. A total of 40 cases and 40 controls were included in the study.

Genomic DNA was isolated from the whole blood samples collected from children infected with TB and healthy controls using Qiagen QIAamp DNA Blood mini kit following the manufacture's guidelines. Nanodrop spectrophotometer 2000 (Thermo Scientific USA) was used to measure the concentration and purity of the isolated genomic DNA.

\section{Genome wide DNA Methylation- $5 \mathrm{mC}$ Quantification}

The quantity of genome wide 5- methyl cytosine $(5-\mathrm{mC})$ concentration was detected using 5-mC DNA ELISA kit (Zymo 
Research, USA). Following the manufacture's guideline approximately 100ng of genomic DNA was used for the assay. 100ng of genomic DNA was made to a total volume of $100 \mu \mathrm{L}$ using 5-mC coating buffer. Subsequently denaturation of the DNA samples was done by heating at $98^{\circ} \mathrm{C}$ for 5 min in a thermocycler (Eppendorf Master cycler, Germany) and the samples were immediately shifted to ice for $10 \mathrm{~min}$. The samples were then added to a pre-coated 96 welled ELISA microtiter plate to detect the methylation level of genomic DNA. After $1 \mathrm{~h}$ of incubation at $37^{\circ} \mathrm{C}$ the wells were washed thrice with wash buffer and $200 \mu \mathrm{L}$ of $5 \mathrm{mC}$ buffer was added to each well and incubated for $30 \mathrm{~min}$ at $37^{\circ} \mathrm{C}$. The direct conjugant of 5methylcytosine and the secondary antibody were stocked in a ratio of 1:2 using ELISA buffer $(2000 \mu \mathrm{L}) .100 \mu \mathrm{L}$ of this conjugants stock were added to each well and incubated at $37^{\circ} \mathrm{C}$ for $1 \mathrm{~h}$. Following the washing step thrice $(200 \mu \mathrm{L}$ of wash buffer) after incubation to remove the unbound substrate- antibody conjugates, the wells were loaded with $100 \mu \mathrm{L}$ of enhancer solution to enhance the activity of horseradish peroxidase conjugated with the secondary antibody. The activity of horseradish peroxidase with the substrate results in development of color. The intensity of color development varies in each well directly proportional to the concentration of 5-mC content of the DNA sample. Thereupon $1 \mathrm{hr}$ of incubation at room temperature the plate was subjected to measure absorbance at $450 \mathrm{~nm}$ to quantify the 5- methyl cytosine content in a genome. The results were validated by performing in triplicates of each sample.

Standard concentrations of methylated and unmethylated DNA controls were prepared at the concentrations at $0 \%, 5 \%, 10 \%, 25 \%$, $50 \%, 75 \%$ and $100 \%$ to plot a standard curve for comparison (Table 1-5). 100\% methylated and $100 \%$ unmethylated strands supplied with the kit was used as positive and negative control respectively.

\section{Methylation status of Repetitive Elements-} LINE1 and SINE (Alu)

\section{Genomic DNA extraction and Bisulphite Conversion}

Genomic DNA from whole blood as described earlier was isolated to detect the methylation levels of the repetitive elements LINE1 and SINE (Alu). Approximately 500ng of genomic DNA was taken and subjected to bisulphite conversion using EZDNA Methylation - Startup Kit and direct Kit (Zymo Research, USA). Following the treatment with proteinase K, $130 \mu$ Lof bisulphite conversion reagent was added to the samples and placed in a thermocycler with the following temperature settings.

$1.98^{\circ} \mathrm{C}$ for 8 minutes

2. $64^{\circ} \mathrm{C}$ for 3.5 hours

The samples were then transferred to a column treated with $600 \mu \mathrm{L}$ of binding buffer. After a brief centrifugation for $30 \mathrm{secs}$ at > $10,000 \mathrm{xg}, 100 \mu \mathrm{l}$ of wash buffer was added to the column and Centrifuged at $>10,000 \mathrm{xg}$ for 30 seconds. Subsequently $200 \mu \mathrm{l}$ of Desulphonation Buffer was added to the column and let stand at room temperature (20$30^{\circ} \mathrm{C}$ ) for $15-20$ minutes. After incubation the column was centrifuged at $>10,000 \mathrm{xg}$ for 30 seconds. $200 \mu \mathrm{l}$ of Wash Buffer was then added to the column with a brief centrifugation at $>10,000 \mathrm{xg}$ for 30 seconds. The wash step was repeated to remove the unbound particles. Finally, $10 \mu \mathrm{l}$ of Elution Buffer was added directly to the column matrix and centrifuged for 30 seconds at > $10,000 \mathrm{xg}$, to elute the DNA. The volume of elution buffer can vary according to the concentration of the DNA required. 


\section{Methylation Specific -PCR (MSP)}

After bisulphite treatment the methylated cytosines (M) in the genome will remain as cytosines and the unmethylated cytosines (U) would have been converted to uracil. Methylation specific PCR is exclusively to detect the methylation levels of a gene; however, the chance of a gene remaining in unmethylated state is also possible. Considering the fact that the gene of interest may exist in Methylated or unmethylated state, the primers designed were specifically for methylated as well as unmethylated sequence with the respective complementarity.

The promotor sequence retrieved with the transcription start site have been subjected as input sequence in methprimer tool (http://www.urogene.org/methprimer)

(MethPrimer | Tools and Databases | The Li $L a b ., 2019)$ to design primer for methylated and unmethylated sequences respectively. The $\mathrm{CpG}$ islands were detected using the same software so that to trace the methylation in CpG consisting transcription factors or TSS would hinder the transcription abruptly.

MS-PCR was performed twice for each gene (SINE(Alu) and LINE1) considering the possibilities of presence of both $\mathrm{M}$ and $\mathrm{U}$ sequences. One of the reaction mixtures will have primers for methylated sequence and the other will have primers of unmethylated strands to detect the amplification respectively. A reaction volume of $25 \mu 1$ was made to perform MS-PCR with the following temperature settings

$\begin{array}{lcll}\text { Bisulfite Converted DNA } & -1 \mu \mathrm{l} & \text { Initial Denaturation } & 95^{\circ} \mathrm{C} \text { for } 10 \text { min } \\ \text { Forward Primer } & -1 \mu \mathrm{l} & \text { Denaturation } & 95^{\circ} \mathrm{C} \text { for } 30 \sec (35 \text { cycles }) \\ \text { Reverse primer } & -1 \mu \mathrm{l} & \text { Annealing } & 57^{\circ} \mathrm{C} \text { for } 35 \sec (35 \text { cycles }) \\ \text { Master Mix } & -10 \mu l & \text { Extension } & 72^{\circ} \mathrm{C} \text { for } 30 \sec (35 \text { cycles }) \\ \text { Nuclease Free Water } & -12 \mu \mathrm{l} & \text { Final Extension } & 72^{\circ} \mathrm{C} \text { for } 10 \text { min }\end{array}$

The amplicons of methylated and unmethylated reaction from MS- PCR were then detected in $1.5 \%$ agarose gel electrophoresis. Universal methylated human DNA standards supplied with the kit was used as control DNA. The percentage of methylation was calculated according to the $\mathrm{Rf}$ intensity of the product by comparing with fully methylated control DNA strands using ImageQuant LAS 500 (GE Healthcare, UK).

\section{Results and Discussion}

\section{Genome wide global DNA methylation}

Global DNA methylation levels were analyzed from the genomic DNA extracted from the blood samples of all the cases and controls enrolled in the study. Standard graph was constructed from the absorbance ratio of standard controls with known concentrations. The levels of genome wide global DNA methylation were estimated by extrapolating the absorbance ratio of all the cases and controls with that of the standard plot.

Significant difference in percentage of genome wide global DNA methylation level was observed between children infected with TB (cases) and healthy children (controls). The difference in percentage of methylation between the groups was expressed in Median IQR. Distinct hypomethylation was seen in children infected with $\mathrm{TB}$ while healthy controls presented higher methylation levels when compared to that of controls. As proven by many studies, hypomethylated state of a genome implies that the physiological niche is in a stimulus of the underlying disease pathogenesis and prognosis. Thus, hypomethylated state of the genome in cases is more likely related with the pathogenesis of tuberculosis. The percentage of global DNA methylation level in cases was 9\% (IQR, 7\%$10 \%$ ) and in healthy controls percentage of global DNA methylation level was 22\% (IQR, 
$18 \%-24 \%) \mathrm{P}<0.0001$. The median distribution of percentage of global methylation among different forms of TB showed similar percentage of methylation levels among Pulmonary (9\% IQR (7-10) \%), and Extra Pulmonary TB (9\% (7-10) \%). However, children presenting multiorgan involved disseminated form of TB (6\% (5.25-6) \%) showed distinct difference in percentage of methylation with that of Pulmonary and Extra pulmonary TB $(\mathrm{P}=0.017)$. Further analysis was carried out to differentiate the levels of global methylation with respect to gender and age. No significant difference in the percentage of genome wide DNA methylation was found between male and female children. Similarly, the levels of methylation did not vary across different age group of children.

Genome wide DNA methylation Analysis of LINE1 and SINE(Alu) Repetitive Elements (REs)

Methylation pattern of the repetitive elements LINE 1 and SINE(Alu) have been studied to figure out the association of methylation pattern in response to disease prognosis and severity.

Methylation Specific PCR was performed with respective primers to analyze the methylation status of LINE1 and SINE(Alu). Subsequently the PCR products were run in gel electrophoresis and the image was documented. Based on the intensity of the band comparing with that of $100 \%$ methylated and $100 \%$ unmethylated controls the percentage methylation was calculated.

Significant difference in the percentage of methylation of LINE1 and SINE(Alu) was observed between TB cases and controls. The difference in percentage of methylation was expressed in median IQR. The median percentage of LINE1 methylation among cases was $22 \%$ with an IQR ranging between
20-26\% and healthy controls showed median of $67 \%$ (IQR 62-70\%) LINE1 methylation. The median percentage of SINE(Alu) methylation in cases was 27\% (IQR 24-30\%) while controls presented a median of $65 \%$ (IQR 58-68\%) SINE Methylation. The methylation pattern of Repetitive Elements among cases and controls showed distinct difference. As anticipated the children infected with TB showed hypomethylated pattern while healthy controls showed a prominent hypermethylated pattern of repetitive elements.

Further analysis was carried out to determine the difference in the levels of LINE1 and SINE(Alu) methylation among children presented pulmonary tuberculosis, extra pulmonary tuberculosis and multiorgan involved disseminated tuberculosis. Similarly difference in methylation between gender and different age group were analyzed.

The pattern of methylation in LINE1 and SINE(Alu) repetitive elements were further analyzed between children infected with different forms of TB. Similar pattern of distribution was observed between children presenting pulmonary, extrapulmonary and multiorgan involved disseminated form of Tuberculosis. Median LINE1 methylation among children with pulmonary TB was $23 \%$ (19-25)\%, while extrapulmonary TB $21 \%$ (20-30)\% and disseminated TB $21 \%$ (19$24) \%$ on comparison no significant difference was inferred $\mathrm{P}=0.77$.

Median SINE(Alu) methylation among children with pulmonary TB was $26 \%$ (24$29) \%$, extrapulmonary TB $28 \%(25-30) \%$ and disseminated TB $27 \%$ (24-31)\%. On comparison no significant difference was observed between the groups $\mathrm{P}=0.53$. Children falling in different age groups does not show difference in the levels of LINE1 and SINE methylation [LINE1, $\mathrm{P}=0.44$ and 
SINE(Alu), $\quad \mathrm{P}=0.47] . \quad$ Indistinguishable difference of methylation levels was recorded with TB [LINE1, $\mathrm{P}=0.19$ and $\operatorname{SINE}(\mathrm{Alu})$, between male and female children infected $\mathrm{P}=0.48]$.

Table.1 Concentration of Positive and Negative Controls

\begin{tabular}{|c|c|c|}
\hline $\begin{array}{l}\text { Percentage of 5-mC } \\
\text { standards }\end{array}$ & $\begin{array}{c}\text { Negative Control } \\
(\mathbf{1 0 0 n g} / \boldsymbol{\mu L})\end{array}$ & Positive Control (100ng/ $\boldsymbol{\mu L})$ \\
\hline $0 \%$ & $10.0 \mu \mathrm{L}$ & $0 \mu \mathrm{L}$ \\
\hline $5 \%$ & $9.5 \mu \mathrm{L}$ & $5 \mu \mathrm{L}$ \\
\hline $10 \%$ & $9.0 \mu \mathrm{L}$ & $1.0 \mu \mathrm{L}$ \\
\hline $25 \%$ & $7.5 \mu \mathrm{L}$ & $2.5 \mu \mathrm{L}$ \\
\hline $50 \%$ & $5.0 \mu \mathrm{L}$ & $5.0 \mu \mathrm{L}$ \\
\hline $75 \%$ & $2.5 \mu \mathrm{L}$ & $7.5 \mu \mathrm{L}$ \\
\hline $100 \%$ & $0.0 \mu \mathrm{L}$ & $10.0 \mu \mathrm{L}$ \\
\hline \multicolumn{2}{|c|}{ Total volume of each standard is $10 \mu \mathrm{L}$ at a concentration of $100 \mathrm{ng} / \mu \mathrm{L}$} \\
\hline
\end{tabular}

Table.2 LINE1 and SINE(Alu) MS-PCR Primers

\begin{tabular}{|c|c|c|c|c|c|}
\hline Gene & \multicolumn{2}{|c|}{ Primer Type } & $\operatorname{Tm}\left({ }^{\circ} \mathbf{C}\right)$ & Primer Sequence (5'-3') & Bp \\
\hline \multirow{4}{*}{ LINE1 } & \multirow[b]{2}{*}{$\mathrm{M}$} & $\mathrm{F}$ & \multirow[t]{2}{*}{56} & TATTAGGGAGTGTTAGATAGTGGGC & \multirow[b]{2}{*}{164} \\
\hline & & $\mathrm{R}$ & & ATAACCCGATTTTCCAAATACGT & \\
\hline & \multirow[b]{2}{*}{$\mathrm{U}$} & $\mathrm{F}$ & \multirow[t]{2}{*}{58} & TAGGGAGTGTTAGATAGTGGGTGT & \multirow[b]{2}{*}{164} \\
\hline & & $\mathrm{R}$ & & AАAАТААСССААТТТТССАААТАСАТ & \\
\hline \multirow{4}{*}{$\begin{array}{l}\text { SINE } \\
\text { (Alu) }\end{array}$} & \multirow[b]{2}{*}{ M } & $\mathrm{F}$ & \multirow[b]{2}{*}{53} & CGGATTATTTGAGGTTAGGAGTTC & \multirow[b]{2}{*}{203} \\
\hline & & $\mathrm{R}$ & & CCAAACTAAAATACAATAACGCGAT & \\
\hline & \multirow[b]{2}{*}{$\mathrm{U}$} & $\mathrm{F}$ & \multirow[b]{2}{*}{58.5} & GTGGATTATTTGAGGTTAGGAGTTT & \multirow[b]{2}{*}{204} \\
\hline & & $\mathrm{R}$ & & CCAAACTAAAATACAATAACACAAT & \\
\hline
\end{tabular}

M- Methylation Specific Primer, U-unmethylation Specific Primer, Tm-Melting temperature, F-Forward Primer, RReverse Primer, bp-base pair in length

Table.3 Relationship of Global DNA Methylation levels between different forms of TB, Age and Gender

\begin{tabular}{|l|c|l|c|}
\hline Type of TB & No. of Cases & Median (IQR) & P value \\
\hline Pulmonary Tuberculosis & 33 & $9 \%(7-10) \%$ & 0.017 \\
\hline Extra Pulmonary TB & 23 & $9 \%(7-10) \%$ & \\
\hline Disseminated (Multiorgan) & 4 & $6 \%(5.25-6) \%$ & \multirow{2}{*}{ P value } \\
\hline Gender & No. of Cases & Median (IQR) & 0.88 \\
\hline Male & 31 & $9 \%(7-10) \%$ & \\
\hline Female & 29 & $9 \%(6.5-10) \%$ & \multirow{2}{*}{ P value } \\
\hline Age & No. of Cases & Median $(\mathbf{I Q R})$ & 0.11 \\
\hline $\mathbf{2}$ to 7yrs & 30 & $8 \%(6.75-9) \%$ & \\
\hline 8 to14 yrs & 30 & $9 \%(7-10) \%$ & \\
\hline
\end{tabular}


Table.4 Methylation pattern of repetitive elements among cases and controls

\begin{tabular}{|l|l|l|l|c|}
\hline Gene & Methylation & \multicolumn{1}{c|}{ Case } & Control & P value \\
\hline LINE 1 & Methylated & 22\% (IQR 20-26\%) & 67\% (IQR 62-70\%) & $\mathrm{P}<0.0001$ \\
\hline SINE(Alu) & Methylated & 27\% (IQR 24-30\%) & $65 \%($ IQR 58-68\%) & $\mathrm{P}<0.0001$ \\
\hline
\end{tabular}

Table.5 Methylation pattern of repetitive elements among cases with different forms of TB, age and gender

\begin{tabular}{|c|c|c|c|c|}
\hline $\begin{array}{l}\text { Name of the } \\
\text { Repetitive } \\
\text { Element }\end{array}$ & Type of TB & No. of Cases & Median (IQR) & $P$ value \\
\hline \multirow[t]{3}{*}{ LINE1 } & Pulmonary Tuberculosis & 33 & $23 \%(19-25) \%$ & \multirow[b]{3}{*}{0.77} \\
\hline & Extra Pulmonary TB & 23 & $21 \%(20-30) \%$ & \\
\hline & $\begin{array}{l}\text { Disseminated } \\
\text { (Multiorgan) }\end{array}$ & 4 & $21 \%(19-24) \%$ & \\
\hline \multirow[t]{3}{*}{ SINE(Alu) } & Pulmonary Tuberculosis & 33 & $26 \%(24-29) \%$ & \multirow[b]{3}{*}{0.53} \\
\hline & Extra Pulmonary TB & 23 & $28 \%(25-30) \%$ & \\
\hline & $\begin{array}{l}\text { Disseminated } \\
\text { (Multiorgan) }\end{array}$ & 4 & $27 \%(24-31) \%$ & \\
\hline $\begin{array}{l}\text { Name of the } \\
\text { Repetitive } \\
\text { Element }\end{array}$ & Gender & No. of Cases & Median (IQR) & $P$ value \\
\hline \multirow[t]{2}{*}{ LINE1 } & Male & 31 & $23 \%(20-28) \%$ & \multirow[t]{2}{*}{0.19} \\
\hline & Female & 29 & $21 \%(19-25) \%$ & \\
\hline \multirow[t]{2}{*}{ SINE(Alu) } & Male & 31 & $28 \%(25-30) \%$ & \multirow[t]{2}{*}{0.48} \\
\hline & Female & 29 & $26 \%(24-30) \%$ & \\
\hline $\begin{array}{l}\text { Name of the } \\
\text { Repetitive } \\
\text { Element }\end{array}$ & Age & No. of Cases & Median (IQR) & $P$ value \\
\hline \multirow[t]{2}{*}{ LINE1 } & 2 to $7 y r s$ & 30 & $22 \%(20-25) \%$ & \multirow[t]{2}{*}{0.44} \\
\hline & 8 to 14 yrs & 30 & $22 \%(19-25) \%$ & \\
\hline \multirow[t]{2}{*}{ SINE(Alu) } & 2 to $7 \mathrm{yrs}$ & 30 & $27 \%(25-30) \%$ & \multirow[t]{2}{*}{0.47} \\
\hline & 8 to $14 \mathrm{yrs}$ & 30 & $26 \%(23-31) \%$ & \\
\hline
\end{tabular}

Fig.1 Standard graph of Methylated DNA controls

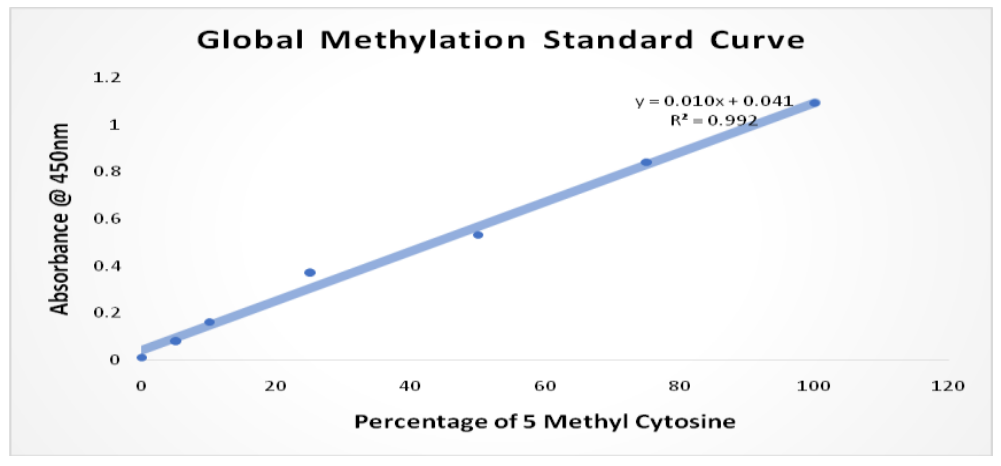


Fig.2 Global DNA Methylation status among cases and controls

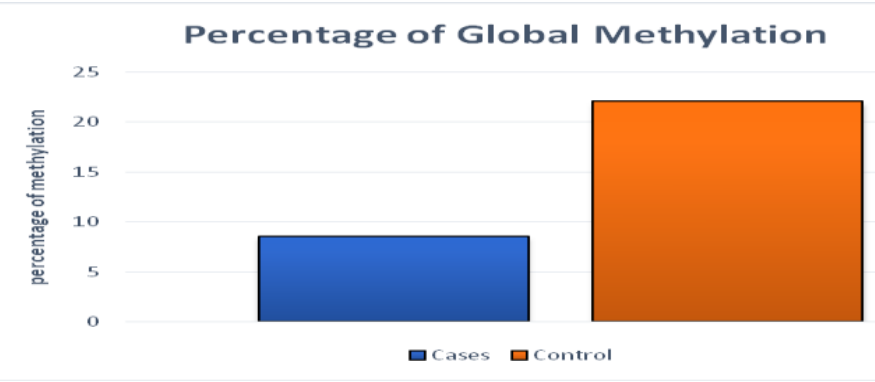

Fig.3 Distribution of Global DNA Methylation levels among cases and controls

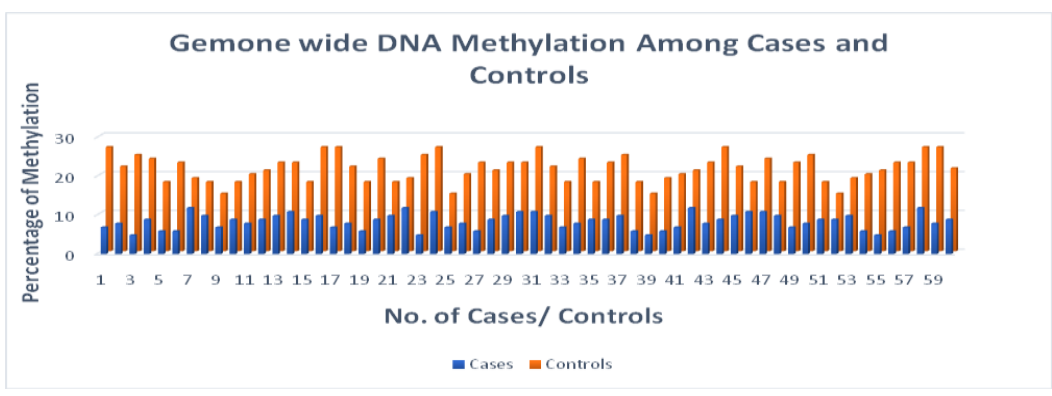

Fig.4 Distribution of Global DNA Methylation levels among different forms of TB

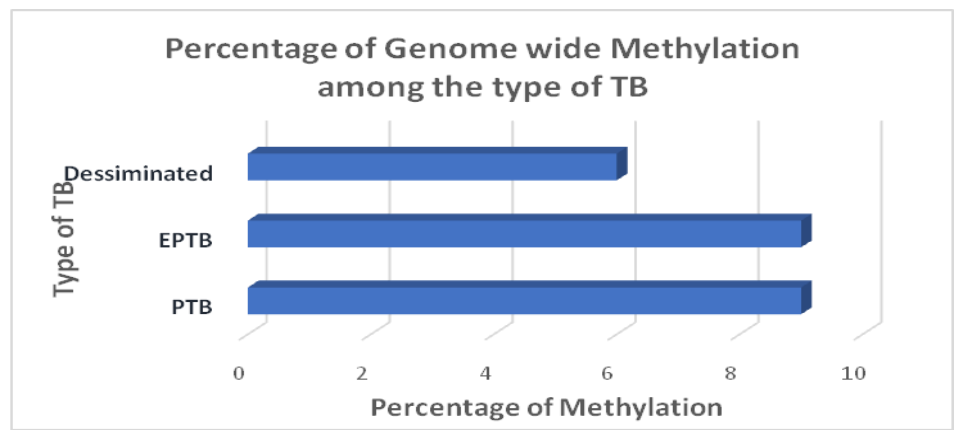

Fig.5 Box plot Representing percentage of methylation LINE1 and SINE Repetitive Elements among cases and controls

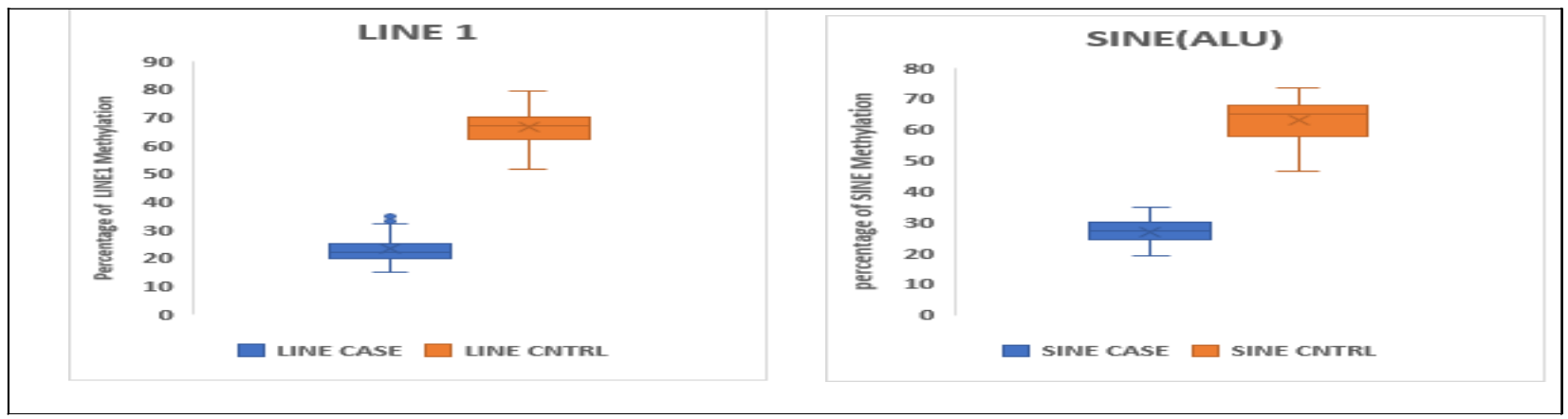


Fig.6 Gel Pics depicting the hypomethylated LINE1 (164bp) and SINE(Alu) (204bp) among cases

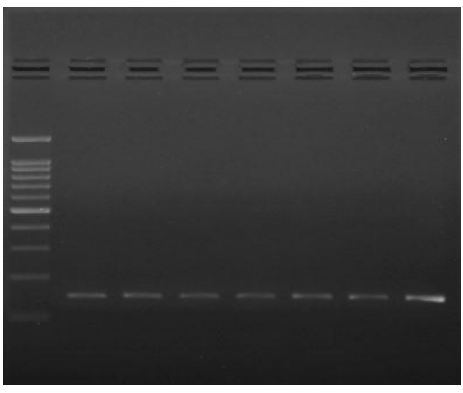

LINE1 Methylation

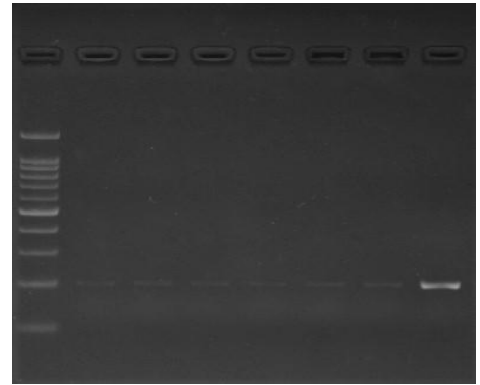

SINE(Alu) Methylation

8th lane contains $100 \%$ methylated control DNA

Characterization of genome-wide DNA hypomethylation in childhood TB

The host immune cells endure massive transformations upon microbial invasion in the transcriptional cascade involved in a prime biological process like establishing immunity (Jenner and Young, 2005). On the other hand, the organism adapts unique survival strategies to alter the regulation of host immune genes. Infectious pathogens initially target the transcription factors of the host and modify their functions. Studies have shown that bacterial infections can alter the signaling pathways that are involved in triggering immunity by directly impeding the transcription or through posttranslational deregulation (Bhavsar et al., 2007; Perrett et al., 2011; Ribet and Cossart, 2010). This selective regulation of particular genes is carried out not only by transcriptional factors but also by epigenetic factors.

In spite of decades of tedious research and discoveries, tuberculosis is still a major concern of public health. Many studies were aimed to enumerate the role and effectiveness of immune response with respect to tuberculosis infection(Lefford, 1975; North, 1973; Orme and Collins, 1983). Particularly, the activation of innate immune molecules on encountering $M t b$ infection plays a vital role in combating the organism(Liu et al., 2017; Van Crevel and Ottenhoff, 2002). Epigenetic regulations involved in prompt activation of immune molecules such as cytokines, macrophages, DCs, NKs etc with regard to $M t b$ infection determines the prognosis of the disease (Esterhuyse et al., 2015; Marimani et al., 2018; Reiner, 2005; Singh et al., 2018).

We found that the children infected with Mycobacterium tuberculosis presented a distinct genome-wide DNA hypomethylation status when compared to that of healthy control children. No distinct difference was observed between children infected with pulmonary and extra pulmonary TB however, children presented with multiorgan involved disseminated form of Tuberculosis showed a significant difference in the pattern of hypomethylation.

The prominent difference of genome-wide DNA methylation observed among cases, controls and with regard to severity of the disease indicates that the genome of host undergoes a genome wide methylation transition upon infection. This transition of global methylation status during the onset of TB infection would have control over the activation of innate immune molecules by regulating the underlying corresponding gene 
expression involved in triggering and establishing immunity. Some of the previous studies proved the effect of DNA methylation in regulating the immune cells(Esterhuyse et al., 2012; Fernández-Morera et al., 2010; Minárovits, 2009; Reiner, 2005; Wilson et al., 2009) and further studies on genome-wide methylation supports the notion that globally hypomethylated DNA aids disease progression during infection(Marr et al., 2014; Scharer et al., 2013; Zhang et al., 2016). Numerous studies on cancer epigenetics supports the same phenomenon that hypomethylation aids in disease progression(Kanai et al., 2001; Stirzaker et al., 2014; Toyota et al., 1999). Thus genomewide hypomethylation in children infected with TB, would either activate the pathways involved in disease progression (Esterhuyse $e t$ al., 2012b; Kim et al., 2012) or hamper the transcription of genes involved in eliciting protective immunity (Chen et al., 2013; Esterhuyse et al., 2012).

Although there was no significant difference observed between children infected with extrapulmonary (9\% IQR (7-10) \%) and pulmonary TB (9\% IQR (7-10) \%), marked difference was observed in cases presented with multiorgan involved disseminated form of TB (6 \% (5.25-6) \%) which can further be inferred as the levels of methylation varies according to the severity of the disease. Healthy children on the control arm showed significantly higher percentage of methylation $22 \%$ (IQR, 18\%-24\%) when compared to cases $9 \%$ (IQR, 7\%-10\%).

No significant difference of global methylation was observed among cases with different age group and gender. Thus, genome-wide 5-mc hypomethylation status in children infected with tuberculosis could act as a potential trigger to deregulate the host transcriptional mechanism to support disease progression.
Characterization of genome-wide DNA methylation analysis of LINE1 and SINE (Alu) Repetitive Elements (REs)

Repetitive Elements (RE) LINE and SINE constitutes $>45 \%$ of the whole genome. REs are often in hypermethylated state to maintain healthy genomic integrity and homeostasis of the body. Hypomethylated state of REs could hinder the transcription of adjacent functional gene by its retrotransposon activity. Some of the transcriptional factor binding sites and nuclear receptors are hampered when the REs are in hypomethylated state. Hence, methylation pattern of the repetitive elements LINE1 and SINE(Alu) have been studied to figure out the association of methylation pattern in response to TB infection.

Remarkable hypomethylated pattern of the repetitive elements LINE1 (22\% (IQR 20$26 \%$ ) and SINE(Alu) (27\% (IQR 24-30\%) were documented in children infected with $\mathrm{TB}$, while healthy controls were documented with hypermethylation of LINE1 (67\% (IQR $62-70 \%$ ) and SINE(Alu) (65\% (IQR 58-68\%). The distinguished hypomethylated state of REs in children infected with TB was found in concurrence with hypomethylated state of genome-wide DNA Methylation. It furthers supports the hypothesis that hypomethylated state repetitive elements contributing to the methylation status of global DNA assists disease progression. However, no evidence of change in pattern of methylation was observed with respect to disease severity, age and gender. Children infected with Pulmonary, Extrapulmonary and disseminated form of multiorgan involved TB showed no difference in the percentage of LINE1 and SINE (Alu) Methylation.

Majority of transposon activity in human is carried out by LINE1 and SINE (Alu) and are typically in hypermethylated state in a balanced niche. LINE1 in hypomethylated 
state could rearrange the genome as transposon insertion sequence and thereby influence the transcription of many functional immune genes(Baba et al., 2018; Consortium, 2001; Elbarbary et al., 2016; Robertson, 2005). Recent studies suggest that hypomethylated state of LINE1 and SINE(Alu) repeats could be a trigger for diseases development and can also be a potential biomarker to detect the prognosis of a disease(Aparicio et al., 2009; Baba et al., 2018; Huen et al., 2016; Marques-Rocha et al., 2016; Wright et al., 2010). In our study similar trend of hypomethylated state was observed in children infected with TB disease. In context to Mycobacterium tuberculosis infection histone monomethylated $\mathrm{H} 3 \mathrm{~K} 4$ state of SINE(Alu) repeats were reported to have widespread control over the transcriptional factors of SP1, p53, c-MYC, ANRIL, NF- kB, MEF2 and ATF families, and nuclear receptors LXR and RAR which plays vital role in macrophage differentiation and elicitation in response to infection and activating innate immunity (Bouttier et al., 2016). Thus, from the supporting evidence from our study, it is inferred that hypomethylated state of repetitive elements LINE1 and SINE(Alu) contributing to the overall hypomethylated state of the genome globally could have negatively influenced the activation of essential innate immune molecules and thereby facilitated TB disease progression.

\section{References}

Aparicio, A., North, B., Barske, L., Wang, X., Bollati, V., Weisenberger, D., Yoo, C., Tannir, N., Horne, E., and Groshen, S. (2009). LINE-1 methylation in plasma DNA as a biomarker of activity of DNA methylation inhibitors in patients with solid tumors. Epigenetics, 4(3), 176-184.

Baba, Y., Yagi, T., Sawayama, H., Hiyoshi,
Y., Ishimoto, T., Iwatsuki, M., Miyamoto, Y., Yoshida, N., and Baba, H. (2018). Long Interspersed Element1 Methylation Level as a Prognostic Biomarker in Gastrointestinal Cancers. Digestion, 97(1), 26-30. https://doi.org/10.1159/000484104

Bhavsar, A. P., Guttman, J. A., and Finlay, B. B. (2007). Manipulation of host-cell pathways by bacterial pathogens. Nature, $\quad 449$ (7164), 827-834. https://doi.org/10.1038/nature06247

Bierne, H., Hamon, M., \&Cossart, P. (2012). Epigenetics and Bacterial Infections. Cold Spring Harbor Perspectives in Medicine, 2(12), a010272-a010272. https://doi.org/10.1101/cshperspect.a0 10272

Bird, A. (2002). DNA methylation patterns and epigenetic memory. Genes and Development, 16(1), 6-21. https://doi.org/10.1101/gad.947102

Bouttier, M., Laperriere, D., Memari, B., Mangiapane, J., Fiore, A., Mitchell, E., Verway, M., Behr, M. A., Sladek, R., Barreiro, L. B., Mader, S., and White, J. H. (2016). Alu repeats as transcriptional regulatory platforms in macrophage responses to $M$. tuberculosis infection. Nucleic Acids Research, 44(22), 10571-10587. https://doi.org/10.1093/nar/gkw782

Chen, C., Pan, D., Deng, A.-M., Huang, F., Sun, B.-L., and Yang, R.-G. (2013). DNA methyltransferases 1 and $3 \mathrm{~B}$ are required for hepatitis $\mathrm{C}$ virus infection in cell culture. Virology, 441(1), 5765.

https://doi.org/10.1016/j.virol.2013.03. 005

Consortium, I. H. G. S. (2001). Initial sequencing and analysis of the human genome. Nature, 409(6822), 860.

Edwards, J. R., Yarychkivska, O., Boulard, M., \&Bestor, T. H. (2017). DNA methylation and DNA 
methyltransferases. Epigenetics and Chromatin, 10(1). https://doi.org/10.1186/s13072-0170130-8

Elbarbary, R. A., Lucas, B. A., \&Maquat, L. E. (2016). Retrotransposons as regulators of gene expression. Science, 351(6274), aac7247-aac7247. https://doi.org/10.1126/science.aac724 7

Esterhuyse, M. M., Linhart, H. G., and Kaufmann, S. H. E. (2012a). Can the battle against tuberculosis gain from epigenetic research? Trends in Microbiology, 20(5), 220-226. https://doi.org/10.1016/j.tim.2012.03.0 02

Esterhuyse, M. M., Weiner, J., Caron, E., Loxton, A. G., Iannaccone, M., Wagman, C., Saikali, P., Stanley, K., Wolski, W. E., Mollenkopf, H.-J., Schick, M., Aebersold, R., Linhart, H., Walzl, G., and Kaufmann, S. H. E. (2015). Epigenetics and Proteomics Join Transcriptomics in the Quest for Tuberculosis Biomarkers. MBio, 6(5), e01187-15.

https://doi.org/10.1128/mBio.0118715

Fernández-Morera, J. L., Calvanese, V., Rodríguez-Rodero, S., MenéndezTorre, E., and Fraga, M. F. (2010). Epigenetic regulation of the immune system in health and disease. Tissue Antigens, 76(6), 431-439. https://doi.org/10.1111/j.13990039.2010.01587.x

Huen, K., Harley, K., Kogut, K., Rauch, S., Eskenazi, B., and Holland, N. (2016). DNA methylation of LINE-1 and Alu repetitive elements in relation to sex hormones and pubertal timing in Mexican-American children. Pediatric Research, 79(6), 855-862. https://doi.org/10.1038/pr.2016.31

Jenner, R. G., and Young, R. A. (2005a).
Insights into host responses against pathogens from transcriptional profiling. Nature Reviews Microbiology, 3(4), 281-294. https://doi.org/10.1038/nrmicro1126

Jin, B., Li, Y., and Robertson, K. D. (2011). DNA Methylation: Superior or Subordinate in the Epigenetic Hierarchy? Genes and Cancer, 2(6), 607-617. https://doi.org/10.1177/194760191039 3957

Kanai Y, Ushijima S, Kondo Y, Nakanishi Y, Hirohashi S. DNA methyltransferase expression and DNA methylation of CPG islands and peri-centromeric satellite regions in human colorectal and stomach cancers. Int $\mathrm{J}$ Cancer. 2001 Jan 15; 91(2): 205-12. doi: $10.1002 / 1097$ 0215(200002)9999:9999<::aidijc1040>3.0.co;2-2. PMID: 11146446

Kim, K. H., An, D. R., Song, J., Yoon, J. Y., Kim, H. S., Yoon, H. J., Im, H. N., Kim, J., Kim, D. J., Lee, S. J., Kim, K.-H., Lee, H.-M., Kim, H.-J., Jo, E.K., Lee, J. Y., and Suh, S. W. (2012). Mycobacterium tuberculosis Eis protein initiates suppression of host immune responses by acetylation of DUSP16/MKP-7. Proceedings of the National Academy of Sciences, 109(20), 7729-7734. https://doi.org/10.1073/pnas.11202511 09

Lefford, M. J. (1975). Transfer of Adoptive Immunity to Tuberculosis in Mice. Infection and Immunity, 11(6), 11741181. https://doi.org/10.1128/IAI.11.6.11741181.1975

Lister, R., Pelizzola, M., Dowen, R. H., Hawkins, R. D., Hon, G., TontiFilippini, J., Nery, J. R., Lee, L., Ye, Z., Ngo, Q.-M., Edsall, L., Antosiewicz-Bourget, J., Stewart, R., 
Ruotti, V., Millar, A. H., Thomson, J. A., Ren, B., and Ecker, J. R. (2009). Human DNA methylomes at base resolution show widespread epigenomic differences. Nature, 462(7271), 315-322. https://doi.org/10.1038/nature08514

Liu, C. H., Liu, H., and Ge, B. (2017). Innate immunity in tuberculosis: Host defense vs pathogen evasion. Cellular and Molecular Immunology, 14(12), 963-975. https://doi.org/10.1038/cmi.2017.88

Marimani, M., Ahmad, A., and Duse, A. (2018). The role of epigenetics, bacterial and host factors in progression of Mycobacterium tuberculosis infection. Tuberculosis, 113 , 200-214. https://doi.org/10.1016/j.tube.2018.10. 009

Marques-Rocha, J. L., Milagro, F. I., Mansego, M. L., Mourão, D. M., Martínez, J. A., and Bressan, J. (2016). LINE-1 methylation is positively associated with healthier lifestyle but inversely related to body fat mass in healthy young individuals. Epigenetics, 11(1), 49-60. https://doi.org/10.1080/15592294.2015 .1135286

Marr, A. K., MacIsaac, J. L., Jiang, R., Airo, A. M., Kobor, M. S., and McMaster, W. R. (2014). Leishmania donovani Infection Causes Distinct Epigenetic DNA Methylation Changes in Host Macrophages. PLoS Pathogens, 10(10), e1004419. https://doi.org/10.1371/journal.ppat.10 04419

MethPrimer | Tools and Databases | The Li Lab. (n.d.). Retrieved March 26, 2019, from http://www.urogene.org/methprimer/

Minárovits, J. (2009). Microbe-induced epigenetic alterations in host cells: The coming era of patho-epigenetics of microbial infections: A review. Acta Microbiologica et Immunologica Hungarica, 56(1), 1-19. https://doi.org/10.1556/AMicr.56.2009 .1 .1

North, R. J. (1973). Importance of thymusderived lymphocytes in cell-mediated immunity to infection. Cellular Immunology, 7(1), 166-176. https://doi.org/10.1016/00088749(73)90193-7

Organization, W. H. O (2018). Roadmap towards ending $T B$ in children and adolescents.

Orme, I. M., and Collins, F. M. (1983). Protection against Mycobacterium tuberculosis infection by adoptive immunotherapy. Requirement for $\mathrm{T}$ cell-deficient recipients. Journal of Experimental Medicine, 158(1), 7483.

https://doi.org/10.1084/jem.158.1.74

Perrett, C. A., Lin, D. Y.-W., and Zhou, D. (2011). Interactions of Bacterial Proteins with Host Eukaryotic Ubiquitin Pathways. Frontiers in Microbiology, 2. https://doi.org/10.3389/fmicb.2011.00 143

Reiner, S. L. (2005). Epigenetic control in the immune response. Human Molecular Genetics, 14(suppl_1), R41-R46. https://doi.org/10.1093/hmg/ddi115

Ribet, D., \&Cossart, P. (2010). SUMOylation and bacterial pathogens. Virulence, 1(6), 532-534. https://doi.org/10.4161/viru.1.6.13449

Robertson, K. D. (2002). DNA methylation and chromatin - unraveling the tangled web. Oncogene, 21(35), 5361-5379. https://doi.org/10.1038/sj.onc.1205609

Robertson, K. D. (2005). DNA methylation and human disease. Nature Reviews Genetics, 6(8), 597-610. https://doi.org/10.1038/nrg1655 
Scharer, C. D., Barwick, B. G., Youngblood, B. A., Ahmed, R., and Boss, J. M. (2013). Global DNA Methylation Remodeling Accompanies CD8 T Cell Effector Function. The Journal of Immunology, 191(6), 3419-3429. https://doi.org/10.4049/jimmunol.1301 395

Singh, M., Yadav, V., and Das, G. (2018). Host Epigenetic Modifications in Mycobacterium tuberculosis Infection: A Boon or Bane. In The Value of BCG and TNF in Autoimmunity (pp. 39-55). Elsevier. https://doi.org/10.1016/B978-0-12814603-3.00004-5

Stirzaker, C., Taberlay, P. C., Statham, A. L., and Clark, S. J. (2014). Mining cancer methylomes: Prospects and challenges. Trends in Genetics, 30(2), 75-84. https://doi.org/10.1016/j.tig.2013.11.0 04

Takai, D., and Jones, P. A. (2002). Comprehensive analysis of $\mathrm{CpG}$ islands in human chromosomes 21 and 22. Proceedings of the National Academy of Sciences, 99(6), 37403745 .

https://doi.org/10.1073/pnas.05241009 9

Toyota, M., Ahuja, N., Ohe-Toyota, M., Herman, J. G., Baylin, S. B., and Issa, J.-P. J. (1999). CpG island methylator phenotype in colorectal cancer. Proc. Natl. Acad. Sci. USA, 6.
Van Crevel, R., and Ottenhoff, T. H. M. (2002). Innate Immunity to Mycobacterium tuberculosis. CLIN. MICROBIOL. REV., 15, 16.

World Health Organization TB Report 2020.

Wilson, C. B., Rowell, E., \&Sekimata, M. (2009). Epigenetic control of T-helpercell differentiation. Nature Reviews Immunology, 9(2), 91-105. https://doi.org/10.1038/nri2487

Wright, R. O., Schwartz, J., Wright, R. J., Bollati, V., Tarantini, L., Park, S. K., Hu, H., Sparrow, D., Vokonas, P., and Baccarelli, A. (2010). Biomarkers of Lead Exposure and DNA Methylation within Retrotransposons. Environmental Health Perspectives, 118(6), 790-795. https://doi.org/10.1289/ehp.0901429

Yadav, V., Dwivedi, V. P., Bhattacharya, D., Mittal, A., and Moodley, P. (2015). Understanding the Host Epigenetics in Mycobacterium tuberculosis. Infection. J Genet Genome Res, 2, 016. Zhang, X., Justice, A. C., Hu, Y., Wang, Z., Zhao, H., Wang, G., Johnson, E. O., Emu, B., Sutton, R. E., Krystal, J. H., and $\mathrm{Xu}, \mathrm{K}$. (2016). Epigenome-wide differential DNA methylation between HIV-infected and uninfected individuals. Epigenetics, 11(10), 750760.

https://doi.org/10.1080/15592294.2016 .1221569

\section{How to cite this article:}

Gayathri Pandurangan, NoyalMariya Joseph and Mahadevan Subramaniyan. 2020. Methylation Pattern of Repetitive Elements in Correlation with Genome Wide Global DNA Methylation in the Prognosis of Paediatric Tuberculosis. Int.J.Curr.Microbiol.App.Sci. 9(12): 308-322. doi: https://doi.org/10.20546/ijcmas.2020.912.041 